
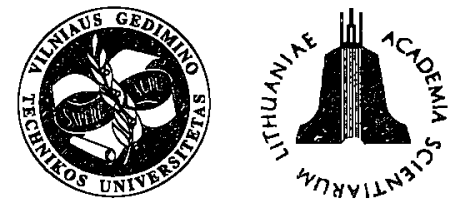

ISSN 1648-4142 TRANSPORT

http:/www.vtu.1t/english/editions

TRANSPORT - 2003, Vol XVIII, No 3, 124-129

\title{
RESEARCH INTO RAIL SIDE WEARING ON CURVES
}

\author{
Inesa Povilaitienė, Igoris Podagèlis \\ Dept of Environmental Engineering, Vilnius Gediminas Technical University, Sauletekio al.11, LT-2009 Vilnius \\ E-mail: kk@ap.vtu.lt
}

Received 200211 20; accepted 20030430

\begin{abstract}
Factors influencing rail side wearing in the curves are described in the article. All of them are divided into uncontrolled, partially controlled and controlled. An experiment was carried out on Lithuanian railway line curves. The experiment proceeding conditions and the obtained results are presented. The object of the experimental research is 19 curves. The investigations of dynamic changes in rail wearing and in rail track geometrical parameters on curves were being carried out for one and a half year.

The experimental results, associated with the railway gauge influence on rail wearing on curves are analyzed more precisely. Measurement results are described using mathematical dependences. According to the dependences it is possible to estimate the influence of gauge on rail side wearing on curves.
\end{abstract}

Keywords: railway; rail; wearing; wearing intensity; gauge; curve.

\section{Introduction}

The problem of intensive rail side wearing on curves exists since the beginning of railway existance. During some periods it used to become even more escalated. This used to happen after substantial changes in railway construction or after the changes in railway and train maintenance conditions [1].

Railway line curves cover a relatively small part of the total railway length. However, they are the ones that condition the reliability and durability of the road, because comparing with the straight sections of the railway, larger horizontal cross forces act on curves. The forces increase when the radius of the curves decreases and train speed increases. The increased train effect forces condition the intensive wearing of upper railroad construction elements and wheel rims. As it is known at present Lithuania is short of funds for the maintenance, repair and modernization of railway lines. Therefore the problem of intensive rail wearing on curves is important from the economical point of view [2].

As for many a long day carried out research of rails and wheel rims wearing and the main wearing models do not have much of a practical benefit, wearing phenomenon remains [3].

The relevance of the problem is governed not only by economical but also by none the less importatnt road safety aspect. Road safety in the railway lines is influenced by road state on curves. Rail bearing force cannot be taken over by any other road element. Hence, the loss of the rail bearing force is the loss of the total rail road bearing force [1]. Therefore it is necessary to estimate and evaluate factors, which have the largest influence on the intensive rail side wearing on curves.

The factors, influencing rail side wearing intensity on curves are analyzed in the article. The factors are taken from the experimental research, carried out on Lithuanian railway line curves from June 2001 till September 2002. Gauge influence on rail wearing intensity on curves is analyzed.

\section{Factors Influencing Rail Side Wearing}

As rail side wearing intensity depends on many factors, it is very difficult to analyze this problem in all aspects during scientific experiments, researches and analyses. The more various factors are joined together, the more reliable and precise results can be obtained. However, the influence of some factors can be estimated only after experimental researches. It can be assumed that such factors are rail track geometrical parameters.

It is suggested to divide the factors that influence rail wearing intensity on curves, into three groups: uncontrolled, partially controlled and controlled.

Uncontrolled factors are railway line plan and profile. They can be changed only during the reconstruction of the railway. Intensive rail wearing on curves is an insufficient reason for plan and profile of the road to be reconstructed. During road projecting it is taken into account that the intensity of rail side wearing proportionally increases, decreasing the radius of the curve. While projecting new or reconstructing present railway lines, it 
is necessary to take into account that railway line plan and profile are the factors, that condition rail wearing intensity on curves during the whole road maintenance period [4].

Partially controlled factors are size of the loads, axial loads and mass of the trains. Regulation of the factors is related with the reorganization of running work. At present it is sought to increase axial loads, improving upper road construction. Rail wearing on curves would decrease decreasing axial loads. For example, if axial load is increased from $12 \mathrm{t} /$ per axis to $18 \mathrm{t} /$ per axis, rail wearing intensity on curves increases 2. 25 times [5]. It is possible to reduce the amount of shipments and train mass, however, such solutions are not effective economically. It can be concluded, that partially controlled factors are the ones that can be changed, however such solutions would not be based economically.

Controlled factors are train speed, rail steel toughness, lubrication and rail track geometrical parameters (gauge, road corrugation, rail tilt and rail rise). The decrement of rail wearing intensity can be reached increasing rail steel toughness and improving its quality. The toughness of the standard rails has increased by $20 \%$ during the last 40 years.

Effectiveness and economical expedience in lubrication curves is a negotiable problem. The application of lubrication in curves increases the rail maintenance time for several times. To assure the effectiveness of applica- tion of lubrication equipment of lubrication has to be modernized, additional equipment and staff for its service is needed. Big investment is necessary for that. One of lubrication disadvantages is that it is difficult to assure the sufficient adhesion between wheels and rails [6].

The influence of geometrical parameters on rail wearing on curves was analyzed as well. However the researches about the importance of not following the standards of intensity of rail wearing on curves, insufficient road service and imperfect road state evaluation system were missing.

The assumptions about the necessity to legitimate new and more precise railway building, reconstruction and service standards have already been announced [1]. The standards of valid deviations are not reasoned enough. Scientifically based principles and methods that would set permissible limits for road construction mounting and deviations, control and evaluation systems during road maintenance are necessary.

\section{Experimental Research and Results}

The object of the experimental research is a dynamic change in rail wearing and in rail track geometrical parameters on Lithuanian railway curves. 19 Lithuanian railway line curves have been selected. The investigated curves and their technical characteristics are presented in Table.

Investigated curves and their characteristics

\begin{tabular}{|c|c|c|c|c|c|c|}
\hline No & $\begin{array}{l}\text { Radius of the } \\
\text { curve, } m\end{array}$ & Type of the rail & $\begin{array}{l}\text { Sleepers and } \\
\text { their } \\
\text { arrangement } \\
\text { (units } / \mathrm{km} \text { ) }\end{array}$ & $\begin{array}{l}\text { Intensity of load } \\
\text { shipmentmln } \\
\text { tgross/km per year }\end{array}$ & $\begin{array}{l}\text { Permissible velocity } \\
\text { pass./freight, } \mathrm{km} / \mathrm{h}\end{array}$ & Rail building year \\
\hline 1 & 607 & UIC60 & r.c., 1840 & 6,0 & $100 / 80$ & 1998 \\
\hline 2 & 654 & UIC60 & r.c., 1840 & 6,4 & $100 / 80$ & 1998 \\
\hline 3 & 883 & UIC60 & r.c., 1840 & 6,0 & $120 / 90$ & 1998 \\
\hline 4 & 915 & UIC60 & r.c., 1840 & 6,4 & $120 / 90$ & 1998 \\
\hline 5 & 620 & UIC60 & r.c., 1840 & 6,0 & $100 / 80$ & 1998 \\
\hline 6 & 601 & UIC60 & r.c., 1840 & 6,4 & $100 / 80$ & 1998 \\
\hline 7 & 610 & UIC60 & r.c., 1840 & 6,0 & $100 / 80$ & 1998 \\
\hline 8 & 633 & $\mathrm{UIC60}$ & r.c., 1840 & 6,4 & $100 / 80$ & 1998 \\
\hline 9 & 1505 & UIC60 & r.c., 1840 & 6,0 & $120 / 90$ & 1998 \\
\hline 10 & 1602 & UIC60 & r.c., 1840 & 6,4 & $120 / 90$ & 1998 \\
\hline 11 & 620 & UIC60 & r.c., 1840 & 5,9 & $100 / 80$ & 1998 \\
\hline 12 & 640 & UIC60 & r.c., 1840 & 6,9 & $100 / 80$ & 1997 \\
\hline 13 & 700 & UIC60 & r.c., 1840 & 5,9 & $100 / 80$ & 1998 \\
\hline 14 & 649 & UIC60 & r.c., 1840 & 6,9 & $100 / 80$ & 1997 \\
\hline 15 & 885 & UIC60 & r.c., 1840 & 5,9 & $120 / 90$ & 1998 \\
\hline 16 & 889 & UIC60 & r.c., 1840 & 6,9 & $120 / 90$ & 1997 \\
\hline 17 & 274 & R65 & Wooden & 12,85 & $40 / 40$ & 2001 \\
\hline 18 & 293 & R65 & Wooden & 16,25 & $40 / 40$ & 2001 \\
\hline 19 & 371 & R65 & Wooden & 16,25 & $40 / 40$ & 2001 \\
\hline
\end{tabular}

r.c. - reinforced concrete 
Measurements of rail wearing and road track parameters were done from June 2001 till September 2002. Three research cycles were carried out for every half of a year. The following parameters were measured:

1. External rail side wearing;

2. Gauge;

3. Size of external rail rise.

Rail track geometrical parameters were measured using a special road geometrical parameters control template. It is difficult to assure precise and reliable measurement results with this device, therefore from four to six measurements had to be done at every point, recording mean value. Rail side wearing was measured using a special protractor. The error of the measurements is $\pm 0,1 \mathrm{~mm}$. Rail side wearing measurement using a special protractor is shown in Fig 1.

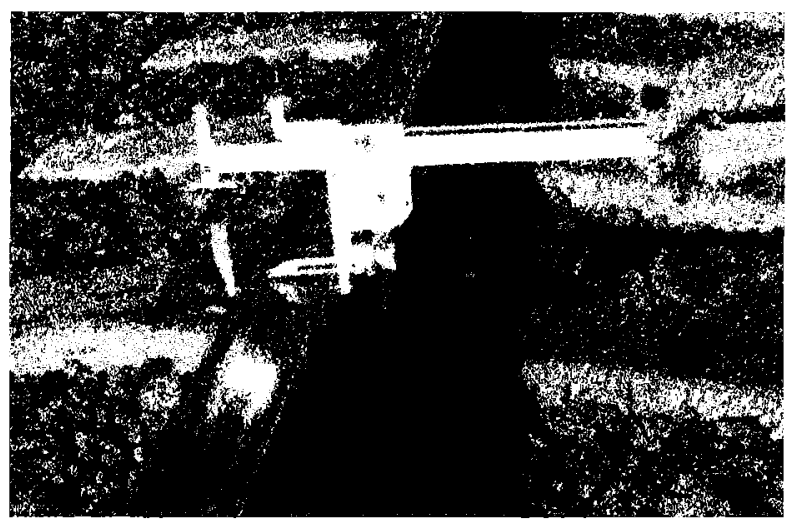

Fig 1. Side wearing measurement on the curve No 4

Measurements were done in the length of an orbicular curve near the axis of every tenth sleeper. Measurements on curves No 1-16 were done at 25 points and on curves No 17, 18 and 19 at 35 points. During every research cycle measurements were done at the same fixed points. Every single time gauge, size of external rail rise and side wearing were measured at every point. Measurement scheme on curves is shown in Fig 2.

The influence of the rail track geometrical parameters (such as rail rise and gauge) on the intensity of rail

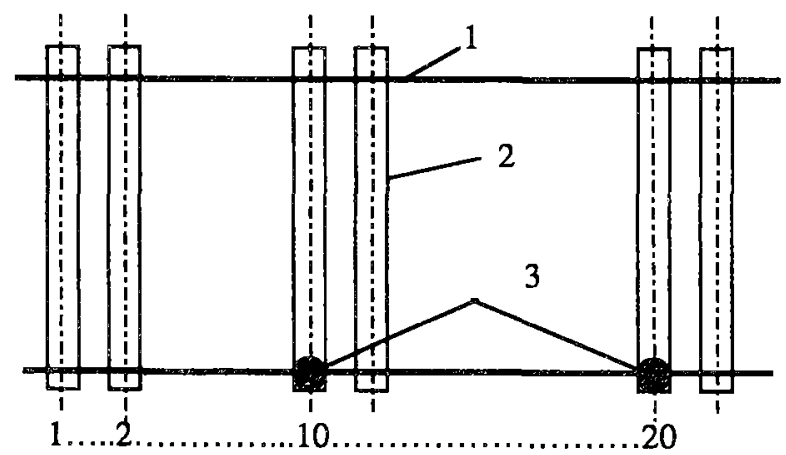

Fig 2. Measurement scheme: 1- rail; 2 - sleeper; 3 - measurement point side wearing $\mathrm{H}^{\prime}$ (intensity of rail side wearing is the size of wearing in millimeters after $1 \mathrm{mlntgross}$ loads have passed) has been investigated separately at every railway line section. However after regressive analysis it emerged that on curves of similar radius a directional line differs very marginally at different sections. As rails of the same type are laid in the sections selected for the research, shipment intensity and other characteristics are alike. Three curves (No 17, 18 and 19) were investigated separately. Radii of the curves are less than $400 \mathrm{~m}$ and side wearing intensity is markedly larger. Besides, permissible velocity on curves No 17,18 and 19 is only 40 $\mathrm{km} / \mathrm{h}$. The significance of the research was that experimental research was started when new rails were laid. Therefore it was possible to examine the dynamic change of wearing from the time the rails were laid till the time the marginal wearing was reached.

During experimental research it was observed that a curve radius has the greatest influence on side wearing intensity. The dependence of side wearing intensity on a curve radius is shown in Fig 3 (data of investigation of curves No 17, 18 and 19 is not included in this dependence). Dependences after experimental research are shown in Fig 3 (blue curve) in this figure. The obtained results were compared with the experimental results of another author [4] (green curve).

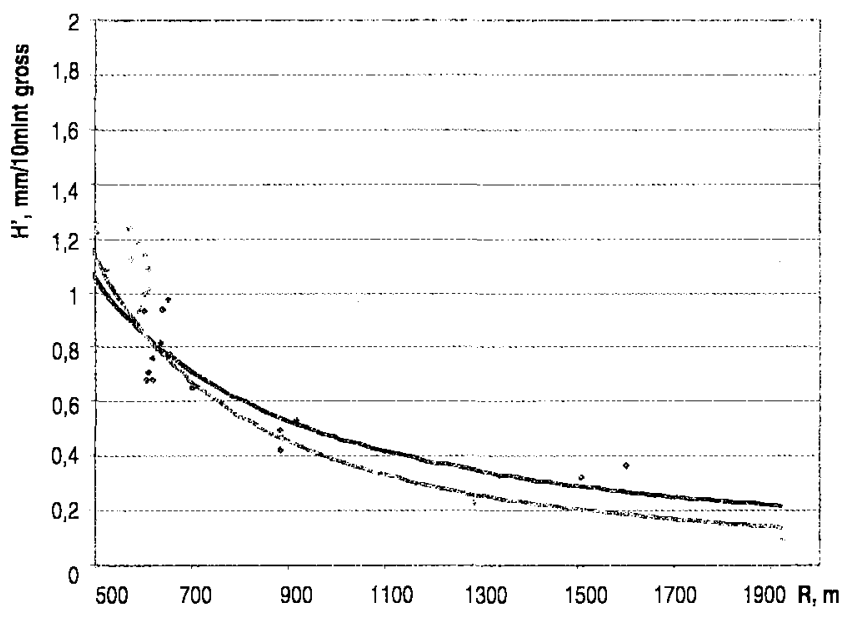

Fig 3. Dependence of rail side wearing intensity on a curve radius:

Dependence obtained by experimental research; .................. Carried out research [4]

Another none the less important factor is the quality of rail steel. Its influence has shown up while carrying out the experimental research. During the experimental research it was observed that in the inter-stations Vilnius - Paneriai and Vilnius - N. Vilnia values of odd and even road side wearing differ markedly. On even roads rails are heat-treated (tempered rails) and on the odd roads the rails are simple. The dependence of rail 
side wearing intensity on curve radius for tempered and non tempered rails is shown in Fig 4. When a curve radius is from $400 \mathrm{~m}$ to $600 \mathrm{~m}$ the wearing intensity of simple rails is $30 \%$ and when a curve radius is from 800 $\mathrm{m}$ to $1000 \mathrm{~m}$ it is respectively $20 \%$ larger than that of the tempered rails.

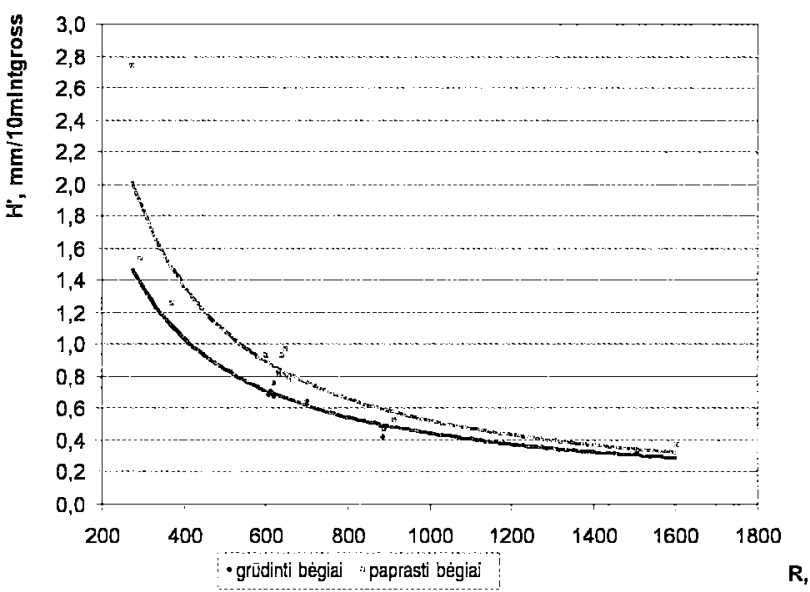

Fig 4. Dependence of rail side wearing intensity on a curve radius

\section{Research of Gauge}

One of the controlled factors that determines rail side wearing intensity is gauge. After the experimental research the dependence of rail side wearing intensity on gauge was defined by a regressive analysis. Linear and polynomial regressive analyses were applied. The comparison of the obtained results was done and the most presumable direction line was determined. The determination of a model and direction line is done separately for the following four curve groups:

1. Curves with tempered and simple rails, type UIC60 are laid (Fig 4). These are curves No 1-16;

2. Curves with radius less than $300 \mathrm{~m}$ and simple rails, type R65 are laid (Fig 5). Curves No 17 and 18;

3. Curves with radius $371 \mathrm{~m}$ and simple rails, type R65 are laid (Fig 6). Curve No 19.

According to the Lithuanian railway service rules [7] track gauge between rail head inner edges has to be $1520 \mathrm{~mm}$ in the straight sections on curves with $350 \mathrm{~m}$ and larger radius. Gauge on curves that have smaller radius has to be the following: when radius is from $349 \mathrm{~m}$ till $300 \mathrm{~m}$, gauge is $1530 \mathrm{~mm}$; when radius is $299 \mathrm{~m}$ or less, gauge is $1535 \mathrm{~mm}$. The deviations of the gauge on the straight lines and on curves must not exceed $6 \mathrm{~mm}$ to the outer side and $4 \mathrm{~mm}$ to the inner side. In the sections where permissible train speed is $50 \mathrm{~km} / \mathrm{h}$ and less, deviations must not exceed $10 \mathrm{~mm}$ to the outer side and 4 $\mathrm{mm}$ to the inner side [7]. These standards are the same as in Russia and they are valid since 1970. Till 1970 gauge on the straight sections and on curves with $350 \mathrm{~m}$ and a larger radius was $1524 \mathrm{~mm}$. Gauge on curves with a smaller radius was the following: when radius is from $349 \mathrm{~m}$ till $300 \mathrm{~m}$, gauge was $1530 \mathrm{~mm}$; when a radius is $299 \mathrm{~m}$ or less, gauge was $1540 \mathrm{~mm}$. The deviations in the straight lines and on curves had to be not larger than $6 \mathrm{~mm}$ to the outer side and not larger than $2 \mathrm{~mm}$ to the inner side. In 1970 it was accepted that the deviation to the inner side has to be not more than $4 \mathrm{~mm}$. As it may be seen, the standards accepted in 1970 have narrowed down gauge and increased permissible deviations to the inner side. As much as we know, the influence of these changes on the train and rails interaction has not been analyzed [8].

Curves with radius larger than $350 \mathrm{~m}$ belong to the analyzed curve groups 1 and 3 . Following the valid railway service rules, gauge on these curves has to be $1520 \mathrm{~mm}$. After the investigations it may be assumed that gauge on curves with a radius from $350 \mathrm{~m}$ to $400 \mathrm{~m}$ should not be less than $1526 \mathrm{~mm}$ (i.e. $1530 \mathrm{~mm}$ gauge with permissible deviations not more that $4 \mathrm{~mm}$ to the inner side). This conclusion is illustrated as dependence in Fig 6. It may be seen that the smallest rail side wearing intensity is when gauge is $1530 \mathrm{~mm}$. When gauge is less than $1526-1525 \mathrm{~mm}$, side wearing intensity sharply increases.

On curves with a radius smaller than $600 \mathrm{~m}$ and when gauge is installed according to the valid standards $(1520 \mathrm{~mm})$, rail side wearing is large (it reaches $1,0-$ $1,2 \mathrm{~mm} / 10 \mathrm{~m}$ lntgross). If to spread out the track to 1524 $\mathrm{mm}$ on curves with such radius, side wearing intensity would decrease to $20 \%$ (Fig 5).

Radii of the curves No. 17 and 18 are smaller than $300 \mathrm{~m}$ (Fig 7), therefore gauge according to the valid standards should be $1535 \mathrm{~mm}$. The results of the experimental research for these curves confirm that when gauge is standard, rail side wearing intensity is the smallest. Therefore, it may be concluded that experimental research for curves with such radius confirm standard requirements.

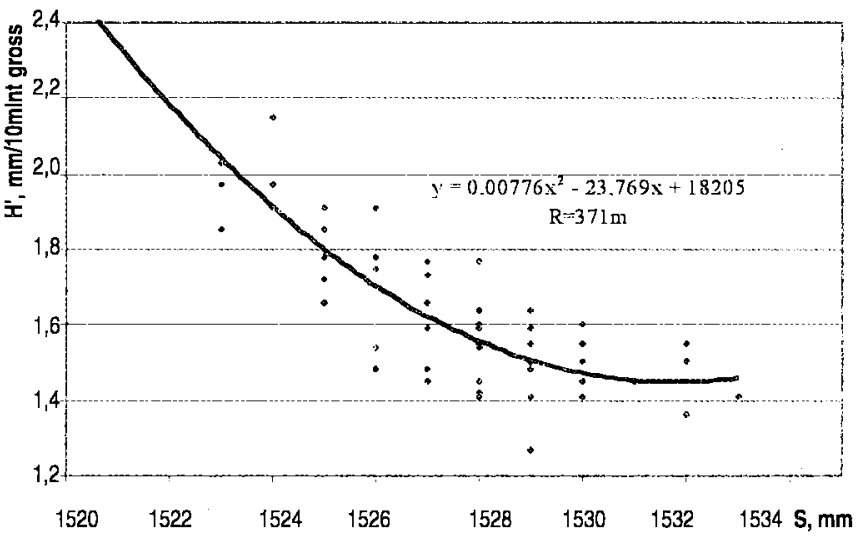

Fig 5. Dependence of rail side wearing intensity on gauge on curves with $\mathrm{R}=371 \mathrm{~m}$ for simple rails, type $\mathrm{R} 65$ 


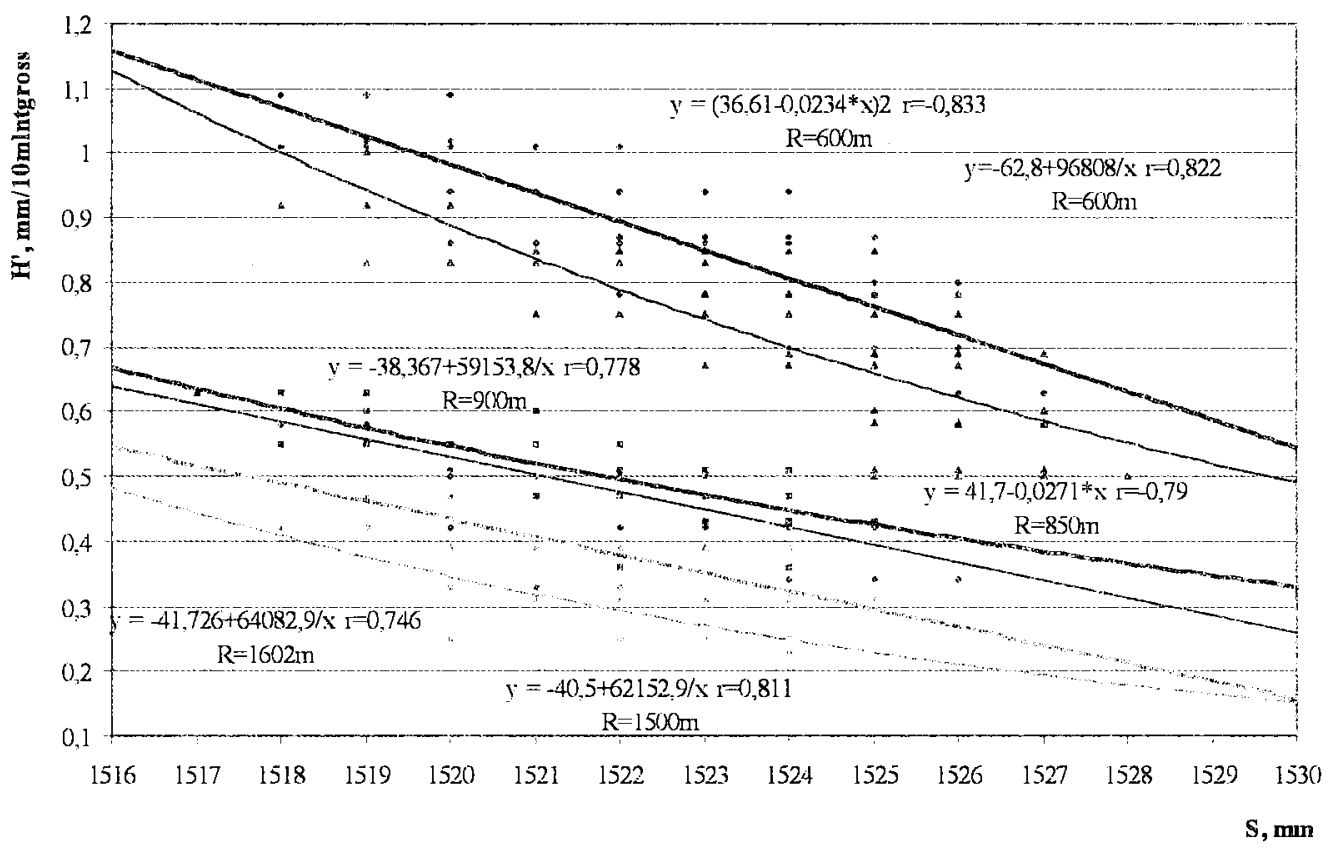

Fig 6. Dependence of rail side wearing intensity on gauge on curves for tempered and simple rails, type UIC60: - simple rails; -...-- - tempered rails

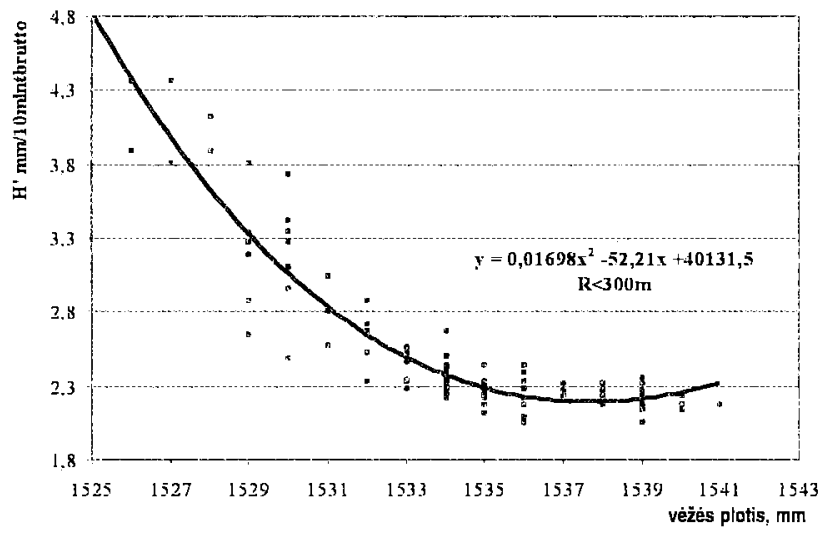

Fig 7. Dependence of rail side wearing intensity on gauge on curves with $\mathrm{R}<300 \mathrm{~m}$ for simple rails, type $\mathrm{R} 65$

\section{Conclusions}

1. The reduction of rail side wearing intensity may be reached regulating controlled factors that condition rail wearing on curves. The main controlled factors are gauge, size of external rail rise and rail lubrication.

2. The radius of the curve has decisive influence on rail side wearing intensity on curves. If the radius of the curve is increased from $300 \mathrm{~m}$ to $600 \mathrm{~m}$, side wearing intensity decreases by $2,1-3,2$ (in this experimental case it decreases by 2.1) and if it is increased from $600 \mathrm{~m}$ to
$900 \mathrm{~m}$ side wearing intensity decreases by $1,6-1,9$.

3. According to experimental research results it is estimated that if gauge of $1530 \mathrm{~mm}$ (at present it is 1520 $\mathrm{mm}$ ) is installed, when the radius of the curve is from $350 \mathrm{~m}$ till $400 \mathrm{~m}$, rail side wearing intensity on curves with such radius will decrease 2 times.

4. If a broadened track of $1524 \mathrm{~mm}$ (instead of $1520 \mathrm{~mm}$ ) is installed on curves with a radius a from 400 $\mathrm{m}$ till $600 \mathrm{~m}$, side wearing intensity will decrease to $20 \%$.

5. If permissible gauge deviations to the inner side were decreased from $4 \mathrm{~mm}$ to $2 \mathrm{~mm}$, side wearing intensity would decrease on curves of any radius.

6. According to experimental research results it is estimated that on curves with a radius less than $299 \mathrm{~m}$, valid gauge standards assure the smallest side wearing intensity.

\section{References}

1. Verigo, M. F. About wheel/rail interaction. Railway Transport (Железнодорожный транспорт), No 5, Moscow: Zeleznodoroznoje delo, 2001, p. $71-74$ (in Russian).

2. Cerniauskaitè, L.; Podagèlis, I.; Sakalauskas, K. New methods of calculation of railway exploitation expenses. Transport Engineering (Transportas), Vol XVI, No 2, Vilnius: Technika, 2001, p. 82-91 (in Lithuanian).

3. Clayton, P. Predicting the wear of rails on curves from labo- 
ratory data. Wear. Paris: Elsevier, Vol 181-183, Part 1, 1995, p. 11-19.

4. Ermakov, V. E. The reasons of rail side wearing. Railway Transport (Железнодорожный транспорт), No 8, Moscow: Zeleznodoroznoje delo, 1997, p. 2-4 (in Russian).

5. Sawley, R.; Reiff, R. Lengthening of service life of rails and wheels. Railway Age, No 6, Chicago: SimmonsBoardman, 1999, p. 44, 46, 48, 49.

6. Podagelis, I. Factors acting on points and inner edges of rails wear. In: Civil engineering and environment. Proceedings. Vilnius: Technika, 1998, p. 91-94.

7. The rules of railway service (Geležinkelio kelio priežiüros taisyklès). Vilnius: SPAB „Lietuvos geležinkeliai", 2000. 213 p. (in Lithuanian).

8. Plotkin, V. S; Kuzmich, L. D.; Samochin, E. N. About the increased wearing of wheels and rails. Railway Transport (Железнодорожный транспорт), No 8, Moscow: Zeleznodoroznoje delo, 1997, p. 51-54 (in Russian). 